\title{
Clinical associations with telomere length in chronic spinal cord injury
}

\author{
David M. Monroe ${ }^{1} \cdot$ Rebekah L. Goldstein ${ }^{2} \cdot$ Merilee A. Teylan $^{2} \cdot$ Jaime E. Hart $^{3} \cdot$ Immaculata DeVivo $^{4}$. \\ Esther H. Orr ${ }^{5}$. Eric Garshick ${ }^{6,7}$
}

Received: 7 April 2019 / Revised: 18 July 2019 / Accepted: 19 July 2019 / Published online: 5 August 2019

(c) The Author(s), under exclusive licence to International Spinal Cord Society 2019

\begin{abstract}
Study design Cross-sectional study

Objectives To determine clinical factors associated with telomere length in persons with chronic spinal cord injury (SCI). Setting Veterans Affairs Medical Center, Boston, MA.

Methods Two hundred seventy-eight participants with chronic SCI provided blood samples for measurement of C-reactive protein (CRP), interleukin-6 (IL-6), and telomere length, completed respiratory health questionnaires, underwent dual X-ray absorptiometry (DXA) to assess body fat, and completed spirometry. High-throughput real-time PCR assays were used to assess telomere length in leukocyte genomic DNA. Linear regression models were used to assess cross-sectional associations with telomere length.

Results Telomere length was inversely related to age $(p<0.0001)$. In age-adjusted models, gender, race, injury duration, $\%$-total and \%-trunk fat, body mass index (BMI), \%-predicted forced vital capacity (FVC) and forced expiratory volume in $1 \mathrm{~s}\left(\mathrm{FEV}_{1}\right)$, chronic cough or phlegm, CRP, IL-6, wheeze, smoking, diabetes, heart disease, chronic obstructive pulmonary disease (COPD), skin ulcer, urinary tract infection (UTI), or chest illness history were not significantly associated with telomere length. There was a suggestive age-adjusted association between persons with the most severe SCI (cervical motor complete and AIS C) and shorter telomere length $(p=0.055)$, an effect equivalent to $\sim 8.4$ years of premature aging. There were similar age-adjusted associations with telomere length between persons using a wheelchair $(p=0.059)$ and persons with chronic urinary catheter use $(p=0.082)$ compared to persons without these characteristics.

Conclusions Our results suggest that clinical characteristics such as decreased mobility and bladder dysfunction that are common in individuals with more severe SCI are associated with shorter telomere length.
\end{abstract}

\section{Introduction}

Recent research has focused on the assessment of telomere length as a biomarker of cellular aging, a potential proxy for

Eric Garshick

Eric.Garshick@va.gov

1 Tufts University School of Medicine, Boston, MA, USA

2 Research and Development Service, VA Boston Healthcare System, West Roxbury, MA, USA

3 Channing Division of Network Medicine, Department of Medicine, Brigham and Women's Hospital and Harvard Medical School; Department of Environmental Health, Harvard T.H. Chan School of Public Health, Boston, MA, USA

4 Channing Division of Network Medicine, Department of cellular health. Telomeres are made up of repeat sequences of nucleotides located at the ends of human chromosomes that function to protect them from degradation and maintain structural integrity. It has been proposed that telomeres are
Medicine, Brigham and Women's Hospital and Harvard Medical School; Department of Epidemiology, Harvard T.H. Chan School of Public Health, Boston, MA, USA

5 Brigham and Women's Hospital and Dept of Epidemiology, Harvard T.H. Chan School of Public Health, Boston, MA, USA

6 Pulmonary, Allergy, Sleep and Critical Care Medicine Section, VA Boston Healthcare System and Harvard Medical School, West Roxbury, MA, USA

7 Channing Division of Network Medicine, Department of Medicine, Brigham and Women's Hospital, Boston, MA, USA

$-$ 
analogous to a "molecular clock" reflecting the number of divisions a cell has undergone. Cells with critically short telomeres are predisposed to enter senescence, undergo apoptosis, and have higher rates of cell death [1]. Reduced telomere length has been consistently associated with increased aging of cells as well as increased exposure of those cells to a variety of environmental, physiologic, and pathologic stressors [2]. Cells and tissues with reduced telomere lengths may therefore reflect advanced damage and reduced longevity, providing a useful biomarker for detecting cell and tissue viability in unique disease states and populations.

The rationale for this study is based on observations that reductions in telomere length in circulating leukocytes have been observed in persons with cardiovascular and chronic respiratory diseases [3]. Associations with reduced telomere length have also been found in neurologic diseases such as multiple sclerosis, systemic inflammatory diseases such as rheumatoid arthritis and cancer, and chronic lifestyle factors such as tobacco use and obesity [4-8]. These findings are consistent with studies indicating that telomeres shorten in response to systemic inflammation, oxidative stress, or other features associated with these physiologic states. Lifestyle and clinical factors common in SCI, including central obesity, a reduction in physical activity, and recurrent infections, are associated with systemic inflammation. Previous studies that we have conducted in chronic SCI at the VA Boston indicate that cardiovascular and pulmonary diseases are the most common causes of death and that these diseases are related to lifestyle and clinical factors that promote systemic inflammation, reduced pulmonary function, and respiratory symptoms [9].

In this study, we investigated whether spinal cord injury (SCI) is a medical condition that promotes accelerated aging at the cellular level by using telomere length as a molecular biomarker. We sought to determine if persons with more severe SCI (cervical tetraplegia) have shorter telomeres than persons with less severe SCI, and if there are clinical characteristics in chronic SCI associated with telomere length. These clinical characteristics include central obesity, systemic inflammation (plasma C-reactive protein [CRP] and interleukin 6 [IL-6]), pulmonary function, respiratory symptoms, comorbid medical conditions, mobility mode, UTI, skin ulcer, and respiratory illness history.

\section{Methods}

\section{Population}

Between August 2009 and April 2012 we recruited 299 individuals into a study of respiratory health among individuals with chronic SCI. Participants were recruited from persons receiving care at VA Boston and from the greater
Boston area as previously described [10-12]. Individuals were eligible if they were 22 years of age or older, were 1 or more years post-injury, had no other neuromuscular disease, did not have a tracheostomy, and were able to breathe without chronic ventilatory support. Participants were eligible regardless of etiology of SCI and testing was scheduled when subjects were free of acute illness. The Institutional Review Board at VA Boston Healthcare System approved the protocol and informed consent was obtained.

\section{Neurological exam, height, and weight}

SCI level and severity was assessed by neurological exam and medical record review and persons underwent measurement of height and weight [13, 14]. Motor incomplete SCI included AIS C (most key muscles below the neurological level grade $<3 / 5$ ) or AIS D (most muscles below the neurological level grade $\geq 3 / 5$ ). For analysis, participants were further grouped into cervical motor complete (AIS A or B) and cervical AIS C, high thoracic (T1-T6) complete (AIS A or B) and AIS C, others with $\mathrm{T} 7$ or below motor complete (AIS A or B) or AIS C, and all others (AIS D's).

\section{Other clinical characteristics}

A fifth generation GE Healthcare iDXA scanner was used to assess $\%$ total body and \% trunk fat and spirometry was conducted as previously described [12, 15]. A questionnaire based on American Thoracic Society Division of Lung Diseases ATS DLD-78 was used to obtain a history of cigarette smoking and comorbid medical diseases [16]. Hypertension, diabetes, and asthma were defined based on report of a diagnosis by a doctor, and chronic obstructive pulmonary disease (COPD) was defined as either doctordiagnosed emphysema or chronic bronchitis. Heart disease was defined as treatment for "heart trouble" reported on the health questionnaire in the 10 years prior to study entry. Participants were asked to report if a chest illness kept them off work, indoors at home, or in bed in the previous one and 3 years, if they currently had a urinary tract infection (UTI) or a skin ulcer, or if they had experienced either in the past one and 3 years, and how they usually passed urine (indwelling, intermittent, condom, or no catheterization). Any wheeze was defined as wheeze or whistling in chest with a cold, occasionally apart from colds, or on most days or nights. Persistent wheeze included reported wheezing with a cold and apart from colds, or wheeze on most days or nights. Chronic cough was defined as cough on most days for 3 consecutive months of the year, and chronic phlegm was defined as phlegm on most days for 3 consecutive months of the year. Usual mobility mode (more than $50 \%$ of the time) was ascertained in four categories: motorized wheelchair use, hand-propelled wheelchair use, 
walk with aid such as crutch or cane, or walk without assistance.

\section{Biochemical analyses}

Plasma samples were obtained at each study visit, during which they were drawn into an EDTA tube and immediately delivered to a core blood research laboratory. The samples were centrifuged for $15 \mathrm{~min}$ at $2600 \mathrm{rpm}(1459 \times g)$ at $4{ }^{\circ} \mathrm{C}$ and stored at $-80^{\circ} \mathrm{C}$ until batch analysis. High sensitivity CRP concentrations were determined using an immunoturbidimetric assay and IL- 6 was determined by an ultrasensitive enzyme linked immunosorbent assay at the Clinical \& Epidemiologic Research Laboratory, Department of Laboratory Medicine at Children's Hospital in Boston. The CRP assay had a sensitivity of $0.03 \mathrm{mg} / \mathrm{L}$, with day-to-day variability of the assay at concentrations of $0.91,3.07$, and $13.38 \mathrm{mg} / \mathrm{L}$ of $2.81 \%, 1.61 \%$, and $1.1 \%$, respectively. The IL-6 assay had a sensitivity of $0.094 \mathrm{pg} / \mathrm{mL}$, with day-today variabilities of the assay at concentrations of $0.66,1.97$ and $8.16 \mathrm{pg} / \mathrm{mL}$ are $12.2 \%, 7.6 \%$, and $9.9 \%$, respectively.

DNA was extracted from buffy-coat samples using the QIAamp 96 DNA Blood Kit by Qiagen (Hilden, Germany). A high-throughput Real-Time PCR assay to assess relative telomere length in leukocyte genomic DNA that involves determining the ratio of telomere repeat copy number to single-copy gene copy number. This is referred to as the Telomere to Single Gene (T/S) ratio and its value is proportional to the average telomere length. The $\mathrm{T} / \mathrm{S}$ ratio value for all samples is then compared to that of a reference DNA sample to normalize for experimental variations. When an unknown sample is identical to the reference DNA in its ratio of telomere repeat copy number to single-copy gene copy number, the T/S ratio value will be 1 . We used a modified version of Cawthon's Real-Time PCR telomere assay for use in a high-throughput 384-well format with an Applied Biosystems (Foster City, CA) 7900HT PCR System [17]. Briefly, $5 \mathrm{ng}$ of buffy-coat derived genomic DNA wad dried down in a 384-well plate and resuspended in 10 $\mu \mathrm{L}$ of either the Telomere or 36B4 PCR reaction mixture and stored in $4 \mathrm{C}$ upto $6 \mathrm{~h}$. The telomere reaction mixture consists of 1x Qiagen Quantitect Sybr Green Master Mix, $2.0 \mathrm{mM}$ of DTT, $270 \mathrm{nM}$ of Tel-1 primer (GGTTTTT GAGGGTGAGGGTGAGGGTGAGGGTGAGGGT), and $900 \mathrm{nM}$ of Tel-2 primer (TCCCGACTATCCCTATCCCT ATCCCTATCCCTATCCCTA). The reaction proceeds for 1 cycle at $95 \mathrm{C}$ for $10 \mathrm{~min}$, followed by 30 cycles at $95 \mathrm{C}$ for $15 \mathrm{~s}$, and $54 \mathrm{C}$ for $2 \mathrm{~min}$. The $36 \mathrm{~B} 4$ reaction consists of $1 \mathrm{x}$ Qiagen Quantitect Sybr Green Master Mix, $300 \mathrm{nM}$ of 36B4U primer (CAGCAAGTGGGAAGGTGTAATCC), and $500 \mathrm{nM}$ of 36B4D primer (CCCATTCTATCATCA ACGGGTACAA). The 36B4 reaction proceeds for 1 cycle at $95 \mathrm{C}$ for $10 \mathrm{~min}$, followed by 35 cycles at $95 \mathrm{C}$ for $15 \mathrm{~s}$, and $58 \mathrm{C}$ for $1 \mathrm{~min}$ and $10 \mathrm{~s}$. All samples for both the Telomere and single-copy gene (36B4) reactions were performed in triplicate on different plates. Each 384-well plate also contained a 6-point standard curve from $0.625 \mathrm{ng}$ to 20 ng using pooled buffy-coat derived genomic DNA. The purpose of the standard curve is to assess and compensate for inter-plate variations in PCR efficiency. Two different quality control samples were interspersed throughout the dataset in order to assess inter-plate and intra-plate variability of threshold cycle $(\mathrm{Ct})$ values. The $\mathrm{T} / \mathrm{S}$ ratio $(-\mathrm{dCt})$ for each sample is calculated by subtracting the average 36B4 $\mathrm{Ct}$ value from the average Telomere $\mathrm{Ct}$ value. The Relative $\mathrm{T} / \mathrm{S}$ ratio $(-\mathrm{ddCt})$ is determined by subtracting the $\mathrm{T} / \mathrm{S}$ ratio value of the $5 \mathrm{ng}$ standard curve point from the T/S ratio of each unknown sample. The coefficient of variation (CV) of the telomere and 36B4triplicate CT values was all less than $2.5 \%$. A combined inter- and intra-assay $\mathrm{CV}$ calculated from quality control samples was $16.6 \%$.

\section{Analysis}

General linear models (PROC GLM, SAS version 9.4) were used to assess determinants of telomere length. Each clinical characteristic in question was included as an independent variable in a separate model with relative telomere length as the dependent variable and age as the only covariate. CRP and IL-6 were natural log transformed to meet model assumptions. We used analysis of variance (ANOVA) and analysis of covariance (ANCOVA) tests to compare means of categorical groupings. A Tukey adjustment was used for multiple comparisons. Model coefficients for significant findings were compared with the coefficient of the relationship between telomere length and age to estimate the relative degree of additional cellular aging that could be expected for a one-unit increase in each variable.

\section{Results}

Participant characteristics are presented in Table 1. Nine persons did not have buffy-coat samples available, 14 persons requested that their DNA not be analyzed, seven persons were excluded because of another neurologic condition or had recovered from SCI, and one person's telomere analysis was technically unacceptable, leaving 268 persons eligible for analysis. The mean age (SD) was 54.1 (14.4) years (range 25-88) and mean (SD) duration of injury was 18.4 (13.1) years (range 1- 61). There were 219 men (81.7\%); 241 (89.2\%) were white, 17 (6.3\%) were AfricanAmerican, and the remainder either Hispanic, Asian, or Native-American. Sixty-seven $(25.0 \%)$ persons were cervical motor complete and AIS C SCI, and 173 (64.5\%) used either a motorized or hand-propelled wheelchair. 
Table 1 Participant characteristics $(N=268)$

Characteristics

Total

$(n=268)$

Continuous Characteristics

Age (years) [mean, SD]

$54.12 \pm 14.41$

Injury duration (years) [mean, SD]

CRP (mg/L) [median, interquartile range]

IL-6 (pg/mL) [median, interquartile range]

Telomere length [mean, SD]

BMI $\left(\mathrm{kg} / \mathrm{m}^{2}\right)$ [mean, SD]

$\%$ predicted $\mathrm{FEV}_{1}(n=248)$ [mean, SD]

$\%$ predicted FVC $(n=248)$ [mean, $\mathrm{SD}$ ]

Percent fat [mean, SD]

Trunk region, $\%$ fat

Total body, $\%$ fat

$0.04 \pm 10.83$

$36.54 \pm 9.11$

\begin{tabular}{ll}
\hline Categorical Characteristic & $n(\%)$ \\
\hline
\end{tabular}

Sex

Female

Male

Race/ethnicity

White

Black

Other $^{\mathrm{a}}$

49 (18.3)

$219(81.7)$

$239(89.2)$

17 (6.3)

$12(4.5)$

SCI Classification

Motor complete cervical \& AIS C

$67(25.0)$

39 (14.6)

$53(19.8)$

Other motor complete \& AIS C

All AIS D

109 (40.7)

Mobility mode

Motorized wheelchair

Hand-propelled wheelchair

Walk with aid (crutch, cane or similar aid)

Walk without assistance

BMI $\left(\mathrm{kg} / \mathrm{m}^{2}\right)$

Normal $(<25)$

Overweight $(25 \leq \mathrm{bmi}<30)$

Obese $(\geq 30)$

$53(19.8)$

$120(44.8)$

45 (16.8)

$50(18.7)$

$102(38.1)$

$81(30.2)$

85 (31.7)

Skin ulcer history

Now

$33(12.3)$

In the past year

In the past 3 years

$66(24.6)$

$87(32.5)$

Urinary tract infection history

Now

$20(7.5)$

In the past year

In the past 3 years

$112(41.8)$

$160(59.7)$

Urinary catheter use

No catheter use

$110(41.0)$

Periodic catheterization
Table 1 (continued)

\begin{tabular}{lr}
\hline Categorical Characteristic & $n(\%)$ \\
\hline \multicolumn{1}{c}{ Indwelling catheter } & $42(15.7)$ \\
$\quad$ Condom catheter & $27(10.1)$ \\
Heart disease & $29(10.8)$ \\
Hypertension & $100(37.3)$ \\
Diabetes & $45(16.8)$ \\
Chest illness in past year & $35(13.1)$ \\
Chest illness in past 3 years $(n=267)$ & $68(25.5)$ \\
COPD & $28(10.5)$ \\
Asthma & $37(13.8)$ \\
COPD or asthma & $59(22.0)$ \\
Chronic cough & $28(10.5)$ \\
Chronic phlegm & $42(15.7)$ \\
Any wheeze & $124(46.3)$ \\
Persistent wheeze & $45(16.8)$ \\
Cigarette use history & \\
Current & $42(15.7)$ \\
Former & $111(41.4)$ \\
Never & $115(42.9)$ \\
\hline
\end{tabular}

${ }^{\mathrm{a}}$ Asian $=2$, Hispanic $=6$, Native-American $=4$

${ }^{\mathrm{b}}$ High thoracic $=\mathrm{T} 1-\mathrm{T} 6$

Telomere length was significantly inversely related to age $(p<0.0001)$. When analyzed in separate models, the variables of gender, race, injury duration, \%-total fat, \%-trunk fat, \%-predicted FVC, FEV ${ }_{1}, \mathrm{CRP}$, IL-6, history of diabetes, heart disease, COPD, asthma, hypertension, respiratory symptoms (chronic cough, chronic phlegm, any wheeze, persistent wheeze), smoking history, a skin ulcer, or UTI currently or in the past year or 3 years, or any urinary catheter use (indwelling, condom, or intermittent) were not significantly associated with telomere length after adjusting for age (Table 2). There was a suggestive association between SCI severity and telomere length. Persons with the most severe SCI (cervical motor complete and AIS C) had shorter telomeres ( $7.6 \%$ less) compared to others with SCI $(p=0.055$, Table 3$)$. Compared to the coefficient of the effect of age on telomere length, the difference in telomere length with the most severe SCI (cervical motor complete and AIS C) compared to others with SCI was approximately equivalent to 8.4 years of aging (Table 3 ).

There was also a suggestive association between telomere length with mobility mode (Table 3 ). In addition to considering mobility mode in four groups we compared wheelchair users (motorized or hand-propelled) to non-users (walk with or without an aid). The age-adjusted telomere length of persons using any wheelchair was shorter compared to non-users (Table 3, $p=0.059$ ). Similarly, in addition to considering any catheter use (as in Table 2), we also 
Table 2 Effect of age and age-adjusted associations with telomere length $(N=268)$

\begin{tabular}{|c|c|c|c|c|}
\hline Clinical factors, continuous covariates & $\beta$ & SE & $95 \% \mathrm{CI}$ & $p$-value \\
\hline Age (years) & -0.0041 & 0.0006 & $-0.0052,-0.0030$ & $<0.0001$ \\
\hline \multicolumn{5}{|l|}{ Age-adjusted } \\
\hline Injury duration (years) & -0.0009 & 0.0006 & $-0.0021,0.0004$ & 0.167 \\
\hline CRP (mg/L) & -0.0001 & 0.0005 & $-0.0011,0.0009$ & 0.797 \\
\hline IL-6 (pg/mL) & 0.0001 & 0.0017 & $-0.0033,0.0034$ & 0.974 \\
\hline $\mathrm{BMI}\left(\mathrm{kg} / \mathrm{m}^{2}\right)$ & 0.0011 & 0.0014 & $-0.0016,0.0038$ & 0.413 \\
\hline$\%$ Predicted $\mathrm{FEV}_{1}(n=248)$ & 0.00003 & 0.00039 & $-0.00074,0.00080$ & 0.935 \\
\hline$\%$ Predicted FVC $(n=248)$ & -0.00004 & 0.00041 & $-0.00085,0.00076$ & 0.913 \\
\hline \multicolumn{5}{|l|}{ Percent fat } \\
\hline Trunk region, $\%$ fat & -0.0006 & 0.0009 & $-0.0024,0.0012$ & 0.521 \\
\hline Total body, $\%$ fat & -0.0006 & 0.0011 & $-0.0027,0.0016$ & 0.606 \\
\hline $\begin{array}{l}\text { Clinical factors, categorical covariates, } \\
\text { age-adjusted }\end{array}$ & LS Mean & SE & $95 \% \mathrm{CI}$ & $p$-value \\
\hline Sex & & & & 0.928 \\
\hline Female & 0.4675 & 0.0187 & $0.4307,0.5043$ & \\
\hline Male & 0.4656 & 0.0088 & $0.4482,0.4830$ & \\
\hline Race & & & & 0.843 \\
\hline White & 0.4665 & 0.0084 & $0.4499,0.4832$ & \\
\hline Non-white & 0.4613 & 0.0245 & $0.4131,0.5096$ & \\
\hline SCI Classification (four groups) & & & & 0.267 \\
\hline Motor complete cervical \& AIS C & 0.4384 & 0.0162 & $0.4066,0.4703$ & \\
\hline Motor complete high thoracic ${ }^{\mathrm{a}} \&$ AIS C & 0.4719 & 0.0215 & $0.4296,0.5142$ & \\
\hline Other motor complete \& AIS C & 0.4682 & 0.0179 & $0.4329,0.5034$ & \\
\hline All AIS D & 0.4797 & 0.0132 & $0.4536,0.5057$ & \\
\hline BMI Categories & & & & 0.890 \\
\hline Normal $(<25)$ & 0.4704 & 0.0131 & $0.4446,0.4962$ & \\
\hline Overweight $(25 \leq$ bmi $<30)$ & 0.4609 & 0.0145 & $0.4323,0.4895$ & \\
\hline Obese $(\geq 30)$ & 0.4654 & 0.0143 & $0.4372,0.4936$ & \\
\hline Mobility mode & & & & 0.261 \\
\hline Motorized wheelchair & 0.4567 & 0.0179 & $0.4215,0.4919$ & \\
\hline Hand-propelled wheelchair & 0.4528 & 0.0122 & $0.4289,0.4768$ & \\
\hline Walk with aid & 0.4967 & 0.0200 & $0.4574,0.5360$ & \\
\hline Walk without assistance & 0.4796 & 0.0186 & $0.4430,0.5163$ & \\
\hline \multicolumn{5}{|l|}{ Skin Ulcers } \\
\hline Any in the past 3 years & & & & 0.560 \\
\hline Yes & 0.4591 & 0.0142 & $0.4312,0.4870$ & \\
\hline No & 0.4692 & 0.0098 & $0.4500,0.4885$ & \\
\hline In the past year & & & & 0.139 \\
\hline Yes & 0.4448 & 0.0163 & $0.4128,0.4769$ & \\
\hline No & 0.4729 & 0.0092 & $0.4547,0.4910$ & \\
\hline Now & & & & 0.301 \\
\hline Yes & 0.4439 & 0.0228 & $0.3991,0.4887$ & \\
\hline No & 0.4691 & 0.0085 & $0.4523,0.4858$ & \\
\hline \multicolumn{5}{|l|}{ Urinary tract infections } \\
\hline Any in the past 3 years & & & & 0.545 \\
\hline Yes & 0.4618 & 0.0105 & $0.4410,0.4825$ & \\
\hline
\end{tabular}


Table 2 (continued)

\begin{tabular}{|c|c|c|c|c|}
\hline $\begin{array}{l}\text { Clinical factors, categorical covariates, } \\
\text { age-adjusted }\end{array}$ & LS Mean & SE & $95 \% \mathrm{CI}$ & $p$-value \\
\hline No & 0.4722 & 0.0130 & $0.4466,0.4977$ & \\
\hline In the past year & & & & 0.996 \\
\hline Yes & 0.4660 & 0.0127 & $0.4409,0.4911$ & \\
\hline No & 0.4659 & 0.0107 & $0.4448,0.4870$ & \\
\hline Now & & & & 0.108 \\
\hline Yes & 0.4208 & 0.0291 & $0.3636,0.4781$ & \\
\hline No & 0.4696 & 0.0082 & $0.4534,0.4858$ & \\
\hline Type of urinary catheterization & & & & $0.312^{\mathrm{b}}$ \\
\hline Yes & 0.4586 & 0.0108 & $0.4375,0.4798$ & \\
\hline Indwelling catheter & 0.4443 & 0.0203 & $0.4440,0.4999$ & \\
\hline Condom catheter & 0.4383 & 0.0251 & $0.4044,0.4842$ & \\
\hline Intermittent catheterization & 0.4720 & 0.0142 & $0.4375,0.4798$ & \\
\hline No & 0.4761 & 0.0131 & $0.3888,0.4877$ & \\
\hline Chronic cough & & & & 0.522 \\
\hline Yes & 0.4810 & 0.0247 & $0.4322,0.5297$ & \\
\hline No & 0.4642 & 0.0084 & $0.4476,0.4808$ & \\
\hline Chronic phlegm & & & & 0.310 \\
\hline Yes & 0.4472 & 0.0201 & $0.4076,0.4867$ & \\
\hline No & 0.4694 & 0.0087 & $0.4524,0.4865$ & \\
\hline Any wheeze & & & & 0.630 \\
\hline Yes & 0.4618 & 0.0117 & $0.4387,0.4849$ & \\
\hline No & 0.4695 & 0.0109 & $0.4481,0.4910$ & \\
\hline Persistent wheeze & & & & 0.627 \\
\hline Yes & 0.4746 & 0.0195 & $0.4362,0.5131$ & \\
\hline No & 0.4642 & 0.0087 & $0.4470,0.4814$ & \\
\hline Heart disease & & & & 0.518 \\
\hline Yes & 0.4814 & 0.0252 & $0.4319,0.5309$ & \\
\hline No & 0.4641 & 0.0085 & $0.4474,0.4808$ & \\
\hline COPD & & & & 0.489 \\
\hline Yes & 0.4495 & 0.0250 & $0.4002,0.4988$ & \\
\hline No & 0.4679 & 0.0084 & $0.4513,0.4845$ & \\
\hline Asthma & & & & 0.828 \\
\hline Yes & 0.4616 & 0.0214 & $0.4194,0.5039$ & \\
\hline No & 0.4666 & 0.0086 & $0.4497,0.4835$ & \\
\hline COPD or asthma & & & & 0.347 \\
\hline Yes & 0.4518 & 0.0170 & $0.4182,0.4853$ & \\
\hline No & 0.4700 & 0.0090 & $0.4522,0.4877$ & \\
\hline Diabetes & & & & 0.105 \\
\hline Yes & 0.4959 & 0.0200 & $0.4564,0.5354$ & \\
\hline No & 0.4599 & 0.0088 & $0.4427,0.4772$ & \\
\hline Hypertension & & & & 0.362 \\
\hline Yes & 0.4763 & 0.0139 & $0.4490,0.5036$ & \\
\hline No & 0.4598 & 0.0104 & $0.4392,0.4803$ & \\
\hline Cigarette use & & & & 0.658 \\
\hline Current & 0.4505 & 0.0201 & $0.4108,0.4902$ & \\
\hline Former & 0.4723 & 0.0128 & $0.4471,0.4974$ & \\
\hline Never & 0.4655 & 0.0126 & $0.4407,0.4903$ & \\
\hline
\end{tabular}

${ }^{\mathrm{a}}$ High thoracic $=\mathrm{T} 1-\mathrm{T} 6$

${ }^{\mathrm{b}}$ Catheter use (indwelling, intermittent, or condom) vs. no catheter use 
Table 3 Age-adjusted effects of SCI, mobility mode, and catheter use on telomere length for the entire cohort and excluding participants with motor complete cervical and AIS C SCI

\begin{tabular}{|c|c|c|c|c|}
\hline Entire cohort $(N=268)$ & LS Mean or $\beta$ & SE & $95 \% \mathrm{CI}$ & $p$-value \\
\hline \multicolumn{5}{|l|}{ SCI cervical classification } \\
\hline Motor complete cervical \& AIS C & 0.4390 & 0.0161 & $0.4073,0.4706$ & 0.055 \\
\hline Other SCI & 0.4750 & 0.0092 & $0.4569,0.4930$ & \\
\hline Age & -0.0043 & 0.0006 & $-0.0054,-0.0032$ & $<0.0001$ \\
\hline $\begin{array}{l}\text { Difference in mean telomere length } \\
\text { compared to age coefficient }^{\mathrm{a}}\end{array}$ & 8.4 & & & \\
\hline \multicolumn{5}{|l|}{ Wheelchair use } \\
\hline Yes (motorized, hand-propelled) & 0.4541 & 0.0101 & $0.4343,0.4740$ & 0.059 \\
\hline No (walk with or without an aid) & 0.4875 & 0.0138 & $0.4603,0.5147$ & \\
\hline Age & -0.0045 & 0.0006 & $-0.0056,-0.0033$ & $<0.0001$ \\
\hline $\begin{array}{l}\text { Difference in mean telomere length } \\
\text { compared to age coefficent }^{\mathrm{a}}\end{array}$ & 7.4 & & & \\
\hline Urinary catheterization groups & & & & 0.082 \\
\hline Indwelling/condom catheter & 0.4421 & 0.0158 & $0.4111,0.4732$ & \\
\hline No catheter/intermittent & 0.4742 & 0.0092 & $0.4560,0.4924$ & \\
\hline Age & -0.0042 & 0.0006 & $-0.0053,-0.0031$ & $<0.0001$ \\
\hline $\begin{array}{l}\text { Difference in mean telomere length } \\
\text { compared to age coefficient }^{\mathrm{a}}\end{array}$ & 7.6 & & & \\
\hline $\begin{array}{l}\text { Excludes motor complete cervical } \\
\text { and AIS C SCI }(n=201)\end{array}$ & $\beta$ & SE & $95 \% \mathrm{CI}$ & $p$-value \\
\hline \multicolumn{5}{|l|}{ Wheelchair Use } \\
\hline Yes (motorized, hand-propelled) & 0.4596 & 0.0131 & $0.4337,0.4855$ & 0.383 \\
\hline No (walk with or without an aid) & 0.4769 & 0.0141 & $0.4492,0.5047$ & \\
\hline \multicolumn{5}{|l|}{ Urinary catheterization groups } \\
\hline Indwelling/condom catheter & 0.4484 & 0.0282 & $0.3928,0.5040$ & 0.469 \\
\hline No catheter/intermittent & 0.4701 & 0.0099 & $0.4506,0.4895$ & \\
\hline
\end{tabular}

${ }^{a}$ Effects compared to aging calculated by subtracting the difference in mean telomere length for each factor and dividing by the $\beta$ for age from the same regression model. For example, for wheelchair use: $(0.4875-0.4541) / 0.0045=7.4$

compared the telomere length of participants who used a bladder catheter chronically (defined as indwelling or condom) to persons who did not use a catheter chronically (normal urination or intermittent catheterization). Persons who used a catheter chronically had shorter telomere lengths compared to non-chronic catheter users $(p=0.088)$. Due to the overlap of persons with more severe SCI (cervical motor complete and AIS C) with wheelchair and catheter use, it was not possible to include these covariates in multivariable models. However, when persons with severe cervical SCI were excluded from the analysis, persons using a wheelchair or with a chronic urinary catheter (indwelling or condom) still had slightly shorter telomeres (Table 3 ).

\section{Discussion}

In this cross-sectional cohort of individuals with chronic SCI, we analyzed the association between telomere length and a number of clinical characteristics, including changes in physiology that are more common in persons with severe chronic SCI. Adjusting for age, our results suggest that telomere length may be reduced in persons with the most severe SCI (cervical motor complete and AIS C) compared to those with less severe injury with an effect equivalent to aging an additional 8.4 years. This finding is consistent with the greater mortality observed in severe tetraplegia compared to others with chronic SCI [9]. Although these observations do not specify the physiologic pathway by which injury and telomere length are related, it suggests that more severe injuries may induce more substantial cellular damage and premature aging than less severe injuries. The factors responsible are uncertain, but may be related to changes in lifestyle factors that accompany the post-injury state. Persons with other neurologic diseases that result in muscular impairment, such as multiple sclerosis, have also been shown to have shortened telomere lengths and increased severity of disease progression [4]. Studies among populations with 
other debilitating diseases have similarly shown reduced telomere lengths in subjects with various types of cancer, heart failure, rheumatoid arthritis, and stroke [5, 18-20].

Mobility mode (persons using a motorized or handpropelled wheelchair vs. no wheelchair use) was an SCI lifestyle characteristic that closely corresponded to SCI severity and there was also a suggestive association with shorter telomeres. Some studies have similarly found that telomere length may be reduced with decreased physical activity and that increased physical activity may increase telomere length over time [21]. Other studies, however, have not found associations between telomere length and physical activity [22].

Similarly, there was suggestive evidence that persons with a greater degree of bladder dysfunction requiring chronic catheter use and potentially a greater risk of chronic infection were more likely to have shorter telomere length. It may also be possible that the use of chronic catheters may lead to reduced telomere lengths directly, possibly by predisposing persons to more UTIs, systemic inflammation, or even urothelial cancers $[23,24]$.

We found no evidence that telomere length is associated with IL-6 or C-reactive protein. This is in contrast to other studies in which individuals with elevated inflammatory biomarkers such as CRP, IL-6, and TNFalpha had reduced telomere lengths. However, these associations have not been consistently replicated across these studies, with some finding associations between telomere length and specific biomarkers while others failed to find those same associations [25, 26]. It is not yet clear which inflammatory biomarkers, if any, have consistently reproducible relationships with telomere length across multiple studies.

Our investigation did not find evidence that body mass index (BMI) or percent body fat are associated with telomere length in chronic SCI. Because obesity has been posited to be a state of increased oxidative stress in the body, it is plausible that obesity and its parameters might lead to reduced telomere length and advanced cellular aging. Several systematic reviews and meta-analyses examining obesity and telomere lengths in recent years found some evidence that BMI and telomere lengths are negatively correlated, although a large portion of the studies were found to be of low to moderate quality and significant heterogeneity existed between studies [8].

Our investigation found no evidence that pulmonary disease, such as a history of COPD or asthma or poor performance on pulmonary function tests, was associated with telomere length in this cohort of SCI patients. Because COPD has been proposed as a disease of accelerated tissue aging and pulmonary function tests have been associated with increased systemic inflammatory biomarkers, it is plausible that patients with pulmonary disease may also demonstrate reduced telomere lengths [27]. The body of research examining pulmonary disease or function and telomere length has found inconsistent results; some studies have found that telomere length is reduced in patients with COPD, while others have not found those associations [28, 29]. Similarly, some studies have found inverse associations between telomere length and pulmonary function while others have not $[30,31]$. Our study also found no evidence of an association between current smoking, heart disease, hypertension, or diabetes with reduced telomere length, which has been suggested in prior studies [7, 32-34]. Our study may have failed to capture these associations because the proportion of subjects with these conditions was relatively small.

This study has several limitations. First, this study cannot determine the temporality or directionality of relationships due to the cross-sectional nature of the data. Second, because of the overlap between mobility mode, chronic catheter use, and level and severity of injury, it was not possible to assess the independent effects of each SCI characteristic. Third, this study does not compare telomere length among the SCI population with that of a control group. The data therefore cannot be extrapolated to show that telomere length differs significantly between the SCI population and the general population and limits its generalizability to populations outside of those with chronic SCI. However, the primary purpose of this study was to examine associations with telomere length in the SCI population specifically, rather than among the general population. Finally, this study may not have captured all pertinent factors involved in the relationship between SCI and telomere length during data collection due to the multifactorial etiology of cellular aging and systemic disease including the use of self-report to obtain a history of medical conditions. Nevertheless, our results suggest that SCI may result in premature aging detectable at the cellular level that may be attributable to the physiologic effects that accompany more severe chronic SCI.

\section{Data availability}

The data for this study are archived at VA Boston Healthcare System and are not publicly available per Department of Veterans Affairs information privacy rules.

Acknowledgements We thank Antonio A. Lazzari, MD, CCD, PhD and Samuel Davis, Boston VA Healthcare System, technician, for DXA data collection. We appreciate the participation of Veterans at VA Boston and others from the greater Boston area with chronic SCI.

Funding This study was supported by VA Rehabilitation Research and Development Merit Review Grants B6618R, I01RX000792, and I01RX000596 from the U.S. Department of Veterans Affairs Rehabilitation Research and Development Service and NIH NIAMS Grant 
R01AR059270. The contents do not represent the views of the U.S. Department of Veterans Affairs or the United States Government. Presented in part in abstract form at the American Thoracic Society International Conference, San Diego in 2014.

Author contributions EG, ID, and JEH contributed to study conception and design. MT, RLG, EO, EG, and DMM were responsible for data analysis with review and interpretation by ID and JEH. DMM, RLG, and EG were responsible for the draft manuscript. All authors contributed to editing and approved the final manuscript.

\section{Compliance with ethical standards}

Conflict of interest The authors declare that they have no conflict of interest.

Statement of ethics The Institutional Review Board at VA Boston Healthcare System approved the protocol (IRB \#2609). We certify that all applicable institutional and governmental regulations concerning the ethical use of human volunteers were followed during the course of this research.

Informed consent Informed written consent was obtained from all volunteers who participated in this study.

Publisher's note: Springer Nature remains neutral with regard to jurisdictional claims in published maps and institutional affiliations.

\section{References}

1. Aubert G, Lansdorp PM. Telomeres and aging. Physiol Rev. 2008;88:557-79.

2. Fasching CL. Telomere length measurement as a clinical biomarker of aging and disease. Crit Rev Clin Lab Sci. 2018;55:443-65.

3. Mui TS, Man J, McElheney J, Sandford A, Coxson H, Birmingham $\mathrm{C}$, et al. Telomere length and chronic obstructive pulmonary disease: evidence of accelerated aging. $\mathrm{J}$ Am Geriatr Soc. 2009;57:2372-4

4. Guan JZ, Guan WP, Maeda T, Guoqing X, GuangZhi W, Makino $\mathrm{N}$. Patients with multiple sclerosis show increased oxidative stress markers and somatic telomere length shortening. Mol Cell Biochem. 2015;400:183-7.

5. Steer SE, Williams FMK, Kato B, Gardner JP, Norman PJ, Hall $\mathrm{MA}$, et al. Reduced telomere length in rheumatoid arthritis is independent of disease activity and duration. Ann Rheum Dis; Lond. 2007;66:476.

6. Willeit P, Willeit J, Mayr A, et al. Telomere length and risk of incident cancer and cancer mortality. JAMA. 2010;304:69-75.

7. Astuti Y, Wardhana A, Watkins J, Wulaningsih W, PILAR Research Network. Cigarette smoking and telomere length: a systematic review of 84 studies and meta-analysis. Environ Res. 2017;158:480-9.

8. Mundstock E, Sarria EE, Zatti H, Louzada FM, Grun LK, Jones $\mathrm{MH}$, et al. Effect of obesity on telomere length: systematic review and meta-analysis. Obesity. 2015;23:2165-74.

9. Garshick E, Kelley A, Cohen SA, Garrison A, Tun CG, Gagnon $\mathrm{D}$, et al. A prospective assessment of mortality in chronic spinal cord injury. Spinal Cord. 2005;43:408-16.

10. Goldstein RL, Walia P, Teylan M, Lazzari AA, Tun CG, Hart JE, et al. Clinical factors associated with $\mathrm{C}$-reactive protein in chronic spinal cord injury. Spinal Cord. 2017;55:1088-95.
11. Garshick E, Walia P, Goldstein RL, Teylan MA, Lazzari AA, Tun $\mathrm{CG}$, et al. Associations between vitamin D and pulmonary function in chronic spinal cord injury. J Spinal Cord Med. 2019;42:171-7.

12. Walia P, Goldstein RL, Teylan M, Lazzari AA, Hart JE, Tun CG, et al. Associations between vitamin D, adiposity, and respiratory symptoms in chronic spinal cord injury. J Spinal Cord Med. 2018;41:667-75

13. Kirshblum SC, Waring W, Biering-Sorensen F, Burns SP, Johansen M, Schmidt-Read M, et al. Reference for the 2011 revision of the International Standards for Neurological Classification of Spinal Cord Injury. J Spinal Cord Med. 2011;34:547-54.

14. Zariffa J, Kramer JLK, Jones LAT, Lammertse DP, Curt A, Steeves JD, European Multicenter Study about Spinal Cord Injury (EMSCI) Study Group. Sacral Sparing in SCI: beyond the S4-S5 and Anorectal Examination. Spine J. 2012;12:389-400.

15. Hart JE, Goldstein R, Walia P, Teylan M, Lazzari A, Tun CG, et al. FEV1 and FVC and systemic inflammation in a spinal cord injury cohort. BMC Pulm Med. 2017;17:113.

16. Ferris BG. Epidemiology Standardization Project (American Thoracic Society). Am Rev Respir Dis. 1978;118(6 Pt 2):1-120.

17. Cawthon RM. Telomere measurement by quantitative PCR. Nucleic Acids Res. 2002;30:e47.

18. Willeit P, Willeit J, Kloss-Brandstätter A, Kronenberg F, Kiechl S. Fifteen-year follow-up of association between telomere length and incident cancer and cancer mortality. JAMA. 2011;306:42-4.

19. Wong LSM, Boer RA, de Samani NJ, Veldhuisen DJ, van Harst P. Telomere biology in heart failure. Eur $\mathrm{J}$ Heart Fail. 2008;10:1049-56.

20. Jin X, Pan B, Dang X, Wu H, Xu D. Relationship between short telomere length and stroke: a meta-analysis. Med (Baltim). 2018;97:e12489.

21. Ornish D, Lin J, Chan JM, Epel E, Kemp C, Weidner G, et al. Effect of comprehensive lifestyle changes on telomerase activity and telomere length in men with biopsy-proven low-risk prostate cancer: 5-year follow-up of a descriptive pilot study. Lancet Oncol. 2013;14:1112-20.

22. Balan E, Decottignies A, Deldicque L. Physical activity and nutrition: two promising strategies for telomere maintenance? Nutrients. 2018;10:1942.

23. Sun X, Jones ZB, Chen X, Zhou L, So K-F, Ren Y. Multiple organ dysfunction and systemic inflammation after spinal cord injury: a complex relationship. J Neuroinflamm. 2016;13:260.

24. Ho C-H, Sung K-C, Lim S-W, Liao C-H, Liang F-W, Wang J-J, et al. Chronic indwelling urinary catheter increase the risk of bladder cancer, even in patients without spinal cord injury. Med (Baltim). 2015;94:e1736.

25. Wong JYY, Vivo ID, Lin X, Fang SC, Christiani DC. The relationship between inflammatory biomarkers and telomere length in an occupational prospective cohort study. PLoS ONE. 2014;9: e87348.

26. Pedroso DCC, Miranda-Furtado CL, Kogure GS, Meola J, Okuka $\mathrm{M}$, Silva $\mathrm{C}$, et al. Inflammatory biomarkers and telomere length in women with polycystic ovary syndrome. Fertil Steril. 2015;103:542-7.e2

27. Sergio LP, da S, Paoli F, de, Mencalha AL, Da, Fonseca AS. Chronic obstructive pulmonary disease: from injury to genomic stability. J Chronic Obstr Pulm Dis. 2017;14:439-50.

28. Cordoba-Lanus E, Espinoza-Jimenez A, Baz-Davila R, Cazorla S, Montejo-de-Garcini A, Aguirre-Jaime A, et al. Telomere shortening and progression in patients with chronic obstructive pulmonary disease (COPD). Am J Respir Crit Care Med. 2016;193:A2340.

29. Andujar P, Courbon D, Bizard E, Marcos E, Adnot S, Boyer L, et al. Smoking, telomere length and lung function 
decline: a longitudinal population-based study. Thorax 2018; 73:283-5.

30. Desai K, Berkman N, Cohen-Manheim I, Sinnreich R, Aviv A, Kark JD. Rapid shortening of leukocyte telomeres is associated with poorer pulmonary function among healthy adults. Respir Med. 2018;145:73-9.

31. Rode L, Bojesen SE, Weischer M, Vestbo J, Nordestgaard BG. Short telomere length, lung function and chronic obstructive pulmonary disease in 46396 individuals. Thorax. 2013;68: 429-35.
32. Tellechea ML, Pirola CJ. The impact of hypertension on leukocyte telomere length: a systematic review and meta-analysis of human studies. J Hum Hypertens. 2017;31:99.

33. Murillo-Ortiz B, Albarrán-Tamayo F, Arenas-Aranda D, BenítezBribiesca L, Malacara-Hernández JM, Martínez-Garza S, et al. Telomere length and type 2 diabetes in males, a premature aging syndrome. Aging Male. 2012;15:54-8.

34. Zhao J, Miao K, Wang H, Ding H, Wang DW. Association between telomere length and type 2 diabetes mellitus: a metaanalysis. PLoS ONE. 2013;8:1-4. 